\title{
Clinicopathological correlates of adrenal Cushing's syndrome
}

\author{
Kai Duan, ${ }^{1,2}$ Karen Gomez Hernandez, ${ }^{3,4}$ Ozgur Mete ${ }^{1,2,4}$
}

${ }^{1}$ Department of Pathology, University Health Network, Toronto, Ontario, Canada ${ }^{2}$ Department of Laboratory Medicine and Pathobiology, University of Toronto, Ontario, Canada

${ }^{3}$ Department of Medicine, University Health Network Toronto, Ontario, Canada ${ }^{4}$ Endocrine Oncology Site Group, Princess Margaret Cancer Centre, Toronto, Ontario, Canada

\section{Correspondence to} Dr Ozgur Mete, 200 Elizabeth Street, 11th floor, University Health Network, Department of Pathology, Toronto, Ontario, Canada M5G 2C4: ozgur.mete2@uhn.ca

Received 25 September 2014 Revised 25 October 2014 Accepted 2 November 2014 Published Online First 25 November 2014

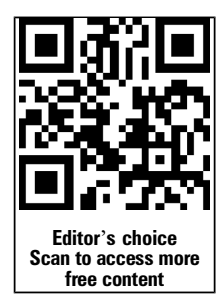

CrossMark

To cite: Duan $\mathrm{K}$, Gomez Hernandez K, Mete 0. J Clin Pathol 2015;68:175-186.

\section{ABSTRACT}

Endogenous Cushing's syndrome is a rare endocrine disorder that incurs significant cardiovascular morbidity and mortality, due to glucocorticoid excess. It comprises adrenal $(20 \%)$ and non-adrenal $(80 \%)$ aetiologies. While the majority of cases are attributed to pituitary or ectopic corticotropin (ACTH) overproduction, primary cortisolproducing adrenal cortical lesions are increasingly recognised in the pathophysiology of Cushing's syndrome. Our understanding of this disease has progressed substantially over the past decade. Recently, important mechanisms underlying the pathogenesis of adrenal hypercortisolism have been elucidated with the discovery of mutations in cyclic AMP signalling (PRKACA, PRKAR1A, GNAS, PDE11A, PDE8B), armadillo repeat containing 5 gene (ARMC5) a putative tumour suppressor gene, aberrant $\mathrm{G}$-protein-coupled receptors, and intra-adrenal secretion of ACTH. Accurate subtyping of Cushing's syndrome is crucial for treatment decisionmaking and requires a complete integration of clinical, biochemical, imaging and pathology findings. Pathological correlates in the adrenal glands include hyperplasia, adenoma and carcinoma. While the most common presentation is diffuse adrenocortical hyperplasia secondary to excess ACTH production, this entity is usually treated with pituitary or ectopic tumour resection. Therefore, when confronted with adrenalectomy specimens in the setting of Cushing's syndrome, surgical pathologists are most commonly exposed to adrenocortical adenomas, carcinomas and primary macronodular or micronodular hyperplasia. This review provides an update on the rapidly evolving knowledge of adrenal Cushing's syndrome and discusses the clinicopathological correlations of this important disease.

\section{INTRODUCTION}

First described in 1932, Cushing's syndrome is a well known clinical entity that reflects chronic exposure of the body to excess glucocorticoids, from either endogenous or more commonly exogenous sources. ${ }^{1-5}$ Accurate epidemiological data on this topic is currently lacking. ${ }^{5}$ The reported incidence of endogenous cases ranges from 2 per million to 3 per million per year, with approximately $10 \%$ of cases occurring in children. ${ }^{1-6}$ Recognition of Cushing's syndrome is critical because the overall mortality from moderate-to-severe hypercortisolism is increased twofold due to macrovascular (myocardial infarction, stroke) and infectious complications. ${ }^{7}$ With modern-day treatments, mortality rates after normalisation of cortisol have been reported to be similar to that of an age-matched population. ${ }^{1-5} 7$
Endogenous Cushing's syndrome is classically divided into corticotropin (ACTH)-dependent and ACTH-independent hypercortisolism. ${ }^{1-12}$ The majority of cases of the ACTH-dependent subtype are caused by a pituitary ACTH-producing adenoma, also known as Cushing's disease (70\% of endogenous Cushing's syndrome; table 1). ${ }^{1-4}$ Other cases are caused by ectopic ACTH secretion (10\%) from a variety of neuroendocrine neoplasms including paraganglioma, phaeochromocytoma and neuroendocrine tumours of various sites (lung, thyroid, thymus, appendix and pancreas). ${ }^{1-6}$ Rare neuroendocrine tumours $(<1 \%)$ can also present with Cushing's syndrome when they secrete corticotropin-releasing hormone $(\mathrm{CRH}){ }^{3}{ }^{10}$ In contrast with the diverse aetiologies of ACTH-dependent Cushing's syndrome, ACTH-independent cases are attributed to primary cortisol-producing adrenocortical lesions (20\%), which may arise sporadically or in the setting of rare genetic syndromes. ${ }^{811-13}$

Accurate subtyping of Cushing's syndrome is essential for treatment decision-making and requires a complete integration of clinical, biochemical, imaging and pathology findings. Pathological correlates in the adrenal glands include hyperplasia, adenoma and carcinoma. ${ }^{11-13}$ While ACTHdependent adrenal hyperplasia is the most common clinical manifestation of endogenous Cushing's syndrome, this entity rarely presents itself in surgical pathology because most cases are treated with transsphenoidal pituitary adenomectomy, ectopic ACTHproducing neuroendocrine tumour resection, radiation or medical therapy. ${ }^{2} 31415$ Therefore, in surgical series of Cushing's syndrome, the most common adrenal pathologies relate to ACTHindependent hypercortisolism (adrenal Cushing's syndrome). ${ }^{16}$ Cortisol-producing adrenocortical adenoma and carcinoma account for, respectively, $55 \%$ and $35 \%$ of cases of adrenal Cushing's syndrome, while primary adrenocortical macronodular and micronodular hyperplasia have been attributed to the remainder $10 \%$ of cases (table 2). ${ }^{23} 11-13$

\section{CLINICAL AND BIOCHEMICAL ASPECTS OF CUSHING'S SYNDROME}

In clinical practice, Cushing's syndrome can present at all ages, with a female predominance. ${ }^{1-5}$ While the overt presentation is clinically unmistakable (central 'truncal' obesity, 'moon facies' and 'buffalo humps'), milder cases are more difficult to diagnose, due to the wide spectrum of manifestations. ${ }^{1-4}$ None of its symptoms are pathognomonic and many of its features (obesity, diabetes, hypertension, fatigue, irritability, depression, decreased concentration and menstrual irregularity) are commonly seen in the general population. ${ }^{1-4} \mathrm{~A}$ clue to the presence 
Table 1 Overview of endogenous Cushing

\begin{tabular}{|c|c|c|c|}
\hline Aetiology & $\begin{array}{l}\text { Associated } \\
\text { biochemical features }\end{array}$ & $\begin{array}{l}\text { Associated } \\
\text { radiological features }\end{array}$ & Associated pathological features \\
\hline Pituitary ACTH ( 70\%) & $\begin{array}{l}\text { ACTH }>15 \mathrm{pg} / \mathrm{mL} \\
\text { CRH+ } \\
\text { HDD+ }\end{array}$ & $\begin{array}{l}\text { Pituitary MRI } \pm \\
\text { BIPSS+ }\end{array}$ & $\begin{array}{l}\text { Pituitary corticotroph adenoma and Crooke's hyaline change in the non-tumorous } \\
\text { corticotrophs; secondary diffuse } \pm \text { nodular adrenal cortical hyperplasia }\end{array}$ \\
\hline $\begin{array}{l}\text { Ectopic ACTH }(\sim 10 \%) \text { or } \\
\text { CRH }(<1 \%)\end{array}$ & $\begin{array}{l}\text { ACTH }>15 \mathrm{pg} / \mathrm{mL} \\
\text { CRH- } \\
\text { HDD- }\end{array}$ & $\begin{array}{l}\text { Pituitary MRI- } \\
\text { BIPSS- }\end{array}$ & Primary neuroendocrine tumour; secondary diffuse adrenal cortical hyperplasia \\
\hline $\begin{array}{l}\text { Primary adrenal } \\
\text { hypercortisolism ( 20\%) }\end{array}$ & $\begin{array}{l}\text { ACTH }<5 \mathrm{pg} / \mathrm{mL} \\
\text { CRH- }\end{array}$ & $\begin{array}{l}\text { Pituitary MRI- } \\
\text { Adrenal CT or MRI+ }\end{array}$ & Adrenal cortical hyperplasia, adenoma and carcinoma \\
\hline
\end{tabular}

ACTH, plasma corticotropin concentration; BIPSS, bilateral inferior petrosal sinus sampling; CRH, corticotropin releasing hormone stimulation test; HDD, high-dose dexamethasone suppression test.

of hypercortisolism is the concurrent development and increasing severity of multiple symptoms. ${ }^{1-4}$ Clinical signs that best discriminate Cushing's syndrome from obesity include easy bruising (figure 1), skin atrophy, unexplained osteoporosis, proximal muscle weakness, reddish purple striae and facial plethora. ${ }^{1}$ In children, weight gain with decreasing growth velocity has been described as a hallmark of Cushing's syndrome. ${ }^{16}$

\section{Diagnostic considerations and pitfalls}

When hypercortisolism is suspected based on clinical presentation, a thorough drug history (oral, injected, topical and inhaled corticosteroids) is necessary to rule out iatrogenic or exogenous aetiologies. $^{1-4}$ Factitious Cushing's syndrome has also been reported in less than $1 \%$ of cases, and can be extremely difficult to recognise. ${ }^{17}$ Other pitfalls in the diagnosis of endogenous Cushing's syndrome include drug interactions and physiological/ physiopathological changes in the hypothalamic-pituitaryadrenal axis. ${ }^{1-4}$ For instance, pseudo-Cushing's states mimic the clinical presentations of Cushing's syndrome and are associated with hypercortisolism, but disappear when the primary condition that led to the Cushing-like state resolves. ${ }^{18}$ Common causes of 'pseudo-Cushing's syndrome' include psychiatric disorders (depression, anxiety) and alcoholism. Certain medications may cause false-positive dexamethasone suppression tests by interfering with dexamethasone metabolism (diphenylhydantoin, carbamazepine, barbiturates) or increasing cortisol-binding globulin (estrogen, mitotane). Moreover, hypercortisolism may be present during certain situations including physical stress (hospitalisation, surgery and pain), malnutrition, anorexia nervosa and hypothalamic amenorrhoea. ${ }^{1-4}$

\section{Biochemical evaluation}

The diagnosis of hypercortisolism is rendered biochemically, using at least two different testing modalities from the following: 24-h urinary free cortisol (two measurements), late-night salivary cortisol (two measurements), 1-mg overnight dexamethasone suppression test and longer low dose dexamethasone suppression test $(2 \mathrm{mg} / \mathrm{d}$ for $48 \mathrm{~h}){ }^{1}$ Interpretation of the test results is dependent on the assay method used and the expertise of an endocrine specialist is often necessary to clarify the caveats of each test. ${ }^{1-4} 8$ After biochemical confirmation of hypercortisolism, further laboratory testing is required to determine the aetiology of Cushing's syndrome (table 1). Corticotroph response is assessed by measuring plasma ACTH levels. ${ }^{2-48}$ A plasma ACTH concentration of less than $5 \mathrm{pg} / \mathrm{mL}(1.1 \mathrm{pmol} / \mathrm{L})$ is in keeping with ACTH-independent Cushing's syndrome, while a concentration of more than $15 \mathrm{pg} / \mathrm{mL}(3.3 \mathrm{pmol} / \mathrm{L})$ is suggestive of ACTH-dependent Cushing's syndrome. ${ }^{2-4} 8$ Borderline plasma
ACTH values between $5 \mathrm{pg} / \mathrm{mL}$ and $15 \mathrm{pg} / \mathrm{mL}$ (1.1 pmol/L and $3.3 \mathrm{pmol} / \mathrm{L}$ ) are equivocal, and a $\mathrm{CRH}$ stimulation test may be helpful in differentiating Cushing's disease from other aetiologies. $^{2-4}$ ACTH and cortisol increases after intravenous administration of CRH is suggestive of Cushing's disease, whereas a blunted response is observed when the aetiology is adrenal. ${ }^{2-4}$ In ACTH-dependent hypercortisolism, CRH stimulation test is also used in conjunction with high-dose dexamethasone suppression test to differentiate between pituitary and ectopic ACTH overproduction; if CRH stimulation and high-dose dexamethasone suppression tests are positive, a petrosal sinus sampling test may not be warranted to confirm or exclude the diagnosis of pituitary ACTH oversecretion. ${ }^{2-4}$

\section{RADIOLOGICAL CONSIDERATIONS IN CUSHING'S SYNDROME}

After biochemical confirmation of hypercortisolism and ACTH status, radiological investigations provide a supplementary method for preoperative subtyping (table 1). In ACTH-dependent Cushing's syndrome, pituitary MRI is the modality of choice to detect a pituitary adenoma. ${ }^{2-4}$ However, given the fact that most cases of Cushing's disease are caused by a pituitary microadenoma $(<1 \mathrm{~cm})$ often not visualised on MRI, bilateral inferior petrosal sinus sampling has become the gold standard test to confirm or exclude pituitary ACTH oversecretion. ${ }^{2-4} 15$ Petrosal venous sampling is not required when dynamic testing results are concordant with a pituitary source and there is a clearly visualised pituitary lesion suggestive of an adenoma and measuring $>6 \mathrm{~mm} .{ }^{19}$ Generally, an inferior petrosal sinus-to-peripheral ACTH ratio at baseline of more than $2: 1$ and a gradient of more than $3: 1$ following CRH stimulation is indicative of Cushing's disease. ${ }^{2-4}$

\section{Assessment of adrenocortical lesions}

In ACTH-independent Cushing's syndrome, adrenal CT scan is the imaging modality of choice to localise and subtype adrenocortical lesions preoperatively (table 2). ${ }^{2-4} 11 \quad 20-24$ The radiological findings for adrenal hyperplasia are often non-specific, showing either enlarged (figures $2 \mathrm{~A}$ and $3 \mathrm{~A}$ ) or normal-sized adrenal glands. ${ }^{11}$ 21-24 Primary pigmented nodular adrenocortical disease occasionally presents as small nodules with hypodense pigment. ${ }^{24-26}$ Primary macronodular hyperplasia may present with massive bilateral adrenal enlargement with multiple nonpigmented nodules, ranging from $1 \mathrm{~cm}$ to $5 \mathrm{~cm}$ (figure $3 \mathrm{~A}$ ). ${ }^{27}$ Adrenocortical adenomas are typically solitary and appear homogeneous, small $(<4 \mathrm{~cm})$, with smooth borders and welldelineated margins (figure $4 \mathrm{~A}) .^{21-23}$ Adrenocortical carcinomas are usually larger in size $(>4 \mathrm{~cm})$ and present heterogeneous contents, irregular margins, and occasional areas of necrosis, 
Table 2 Clinical, biochemical and radiological features of adrenal Cushing

\begin{tabular}{|c|c|c|c|c|c|c|}
\hline & \multirow[b]{3}{*}{ Adrenocortical adenoma } & \multirow[b]{3}{*}{ Adrenocortical carcinoma } & \multicolumn{4}{|c|}{ Primary adrenocortical hyperplasia } \\
\hline & & & \multicolumn{2}{|c|}{ Macronodular hyperplasia } & \multicolumn{2}{|c|}{ Micronodular hyperplasia } \\
\hline & & & ВМАН & C-BMAH & PPNAD & MAD \\
\hline Frequency & $\sim 55 \%$ & $\sim 35 \%$ & \multicolumn{4}{|c|}{ Estimated $10 \%$} \\
\hline Age & All ages & All ages; familial cases in childhood & $\begin{array}{l}\text { Fifth to sixth } \\
\text { decade }\end{array}$ & Early childhood & \multicolumn{2}{|c|}{ Childhood or early adulthood } \\
\hline $\begin{array}{l}\text { Clinical } \\
\text { presentation }\end{array}$ & Mild-to-severe Cushing & $\begin{array}{l}\text { Moderate-to-severe Cushing with } \\
\text { rapid onset and possible virilisation }\end{array}$ & $\begin{array}{l}\text { Mild Cushing } \\
\text { with insidious } \\
\text { onset }\end{array}$ & $\begin{array}{l}\text { Moderate-to-severe } \\
\text { Cushing }\end{array}$ & \multicolumn{2}{|c|}{ Moderate-to-severe Cushing } \\
\hline $\begin{array}{l}\text { Biochemical } \\
\text { features }\end{array}$ & Negative Liddle's test & Negative Liddle's test & $\begin{array}{l}\text { Negative } \\
\text { Liddle's test }\end{array}$ & Negative Liddle's test & $\begin{array}{l}\text { Paradoxical cortisol } \\
\text { response in } \\
\text { Liddle's test }\end{array}$ & $\begin{array}{l}\text { Negative } \\
\text { Liddle's test }\end{array}$ \\
\hline $\begin{array}{l}\text { Radiological } \\
\text { features }\end{array}$ & $\begin{array}{l}\text { Solitary mass, often }<4 \mathrm{~cm} \text {, } \\
\text { defined margins, homogeneous, } \\
<10 \mathrm{HFU} \text {, absolute washout } \\
>60 \%\end{array}$ & $\begin{array}{l}\text { Solitary mass, often }>4 \mathrm{~cm} \text {, irregular } \\
\text { margins, heterogenous, }>10 \mathrm{HFU} \text {, } \\
\text { absolute washout }<60 \%\end{array}$ & \multicolumn{2}{|c|}{$\begin{array}{l}\text { Marked bilateral adrenal enlargement } \\
\text { with multiple large non-pigmented } \\
\text { nodules }(1-5 \mathrm{~cm})\end{array}$} & \multicolumn{2}{|c|}{$\begin{array}{l}\text { Normal or small size adrenal } \\
\text { glands with occasional small } \\
\text { nodules }(<1 \mathrm{~cm})\end{array}$} \\
\hline
\end{tabular}

haemorrhage and calcification (figure 5A; table 2). ${ }^{21-23}$ Given the fact that many adenomas have intracytoplasmic fat resulting in lower attenuation, measurement of the attenuation value is helpful in distinguishing adenomas from carcinoma; tumours

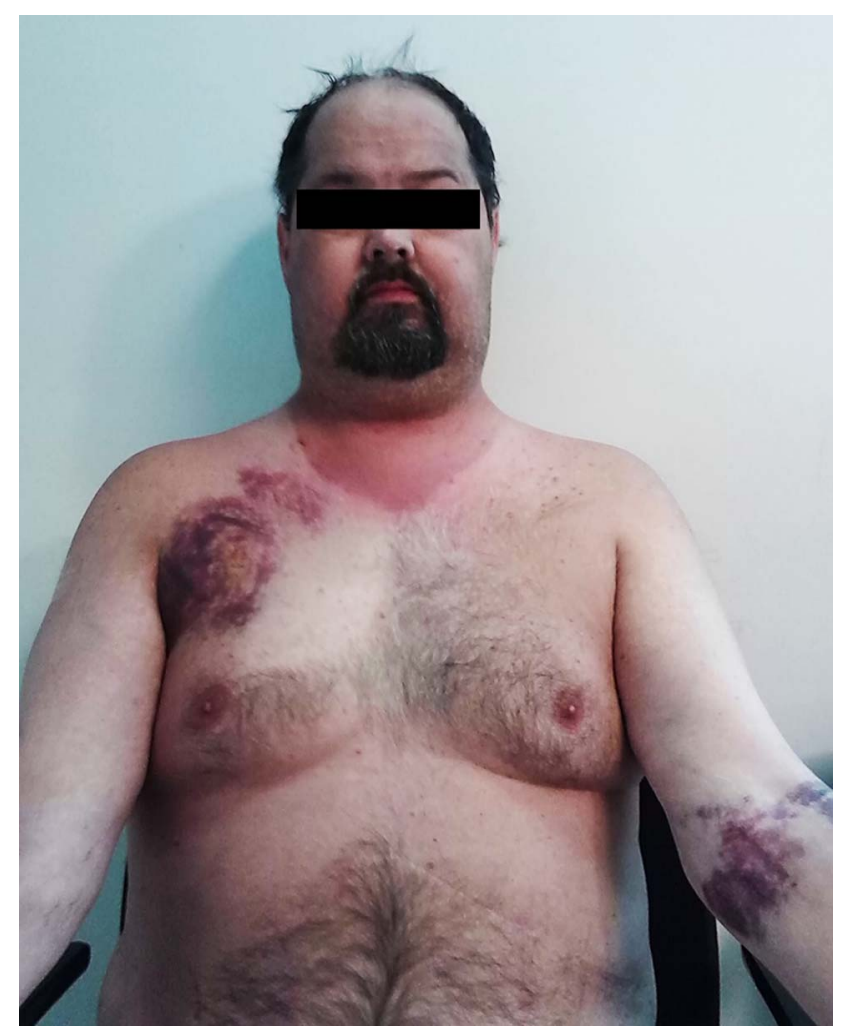

Figure 1 Clinical features of Cushing's syndrome. The overt presentation is clinically unmistakable (central 'truncal' obesity, 'moon facies' and 'buffalo humps'), milder cases are more difficult to diagnose, due to the wide spectrum of manifestations. None of its symptoms are pathognomonic and many of its features are commonly seen in the general population. Clinical signs that have been reported to best discriminate Cushing's syndrome from obesity include easy bruising, skin atrophy, unexplained osteoporosis, proximal muscle weakness, reddish purple striae and facial plethora. with attenuation values below 10 Hounsfield units on noncontrast CT are indicative of adrenocortical adenomas. ${ }^{21-23} 28$ Additionally, on contrast-enhanced CT, an absolute contrast washout of more than $60 \%$ is suggestive of adenoma. ${ }^{21}$

\section{Adrenal incidentalomas}

With the advent of widespread imaging studies, primary hypercortisolism is increasingly diagnosed as part of the recommended workup for adrenal incidentalomas, which are detected for reasons unrelated to adrenal diseases. ${ }^{1}{ }^{29-32}$ The reported incidence of adrenal incidentalomas is approaching the $8.7 \%$ incidence reported in autopsy series, with up to $10 \%$ of cases causing hypercortisolism. ${ }^{29}$ The most common presentation is subclinical Cushing's syndrome, although undiagnosed overt disease may also occur. ${ }^{29-32}$ While the management of subclinical Cushing's syndrome remains an area of controversy, ${ }^{29-32}$ the most recent guidelines suggest that adrenalectomy be offered to patients with worsening hypertension, abnormal glucose tolerance, dyslipidaemia or osteoporosis. ${ }^{29}$ Measurement of fractionated metanephrines and catecholamines is recommended in all cases of adrenal incidentalomas to rule out phaeochromocytoma. ${ }^{29}$ If hypertension is present, an aldosterone-to-renin ratio is also performed to exclude primary aldosteronism. ${ }^{28} 2933$

\section{HISTOPATHOLOGICAL CORRELATES OF CUSHING'S SYNDROME}

The normal adult adrenal gland weighs approximately $4 \mathrm{~g}$ at surgical excision, with an average cortical thickness of 2 mm. ${ }^{16}{ }^{34-38}$ In Cushing's syndrome, histopathological correlates in the adrenal glands include hyperplasia, adenoma and carcinoma. ${ }^{11-13}$ 34-39 While ACTH-dependent adrenal hyperplasia is the most common clinical manifestation of Cushing's syndrome, this entity rarely presents itself in surgical pathology because most cases are treated with transsphenoidal pituitary resection, ectopic tumour resection, radiation or medical therapy. $^{2} 3$ 14-16 Therefore, when confronted with adrenalectomy specimens in the setting of Cushing's syndrome, pathologists are most commonly exposed to cortisol-producing neoplasms and ACTH-independent macronodular and micronodular hyperplasia. ${ }^{11-13} 16$ 34-38 

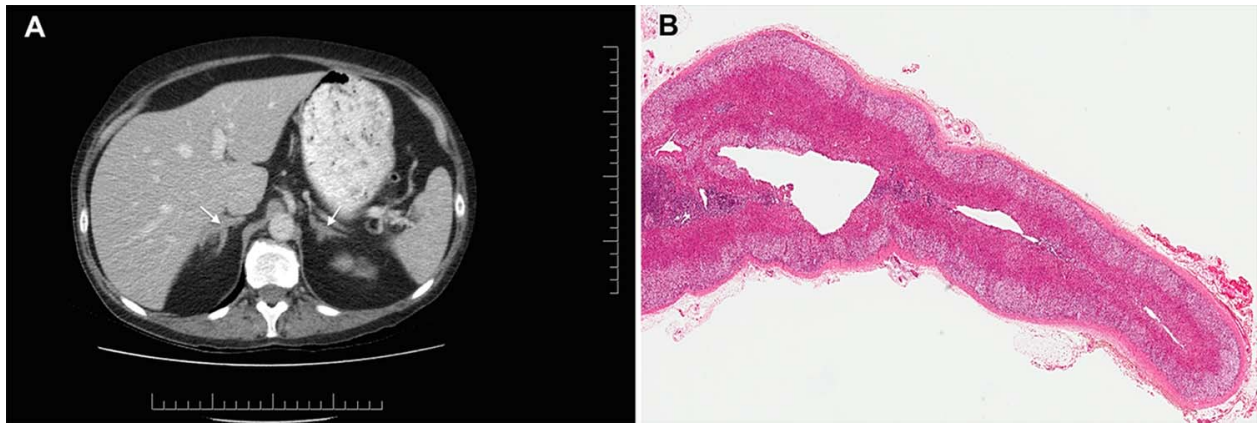

Figure 2 Diffuse hyperplasia. CT shows bilaterally enlarged adrenal glands in a patient with Cushing's disease (A). The adrenal gland is also diffusely enlarged and displays a normal zonation. In contrast to ectopic ACTH-related diffuse hyperplasia, the zonation of the cortex is often conserved in pituitary ACTH-dependent hyperplasia (B).
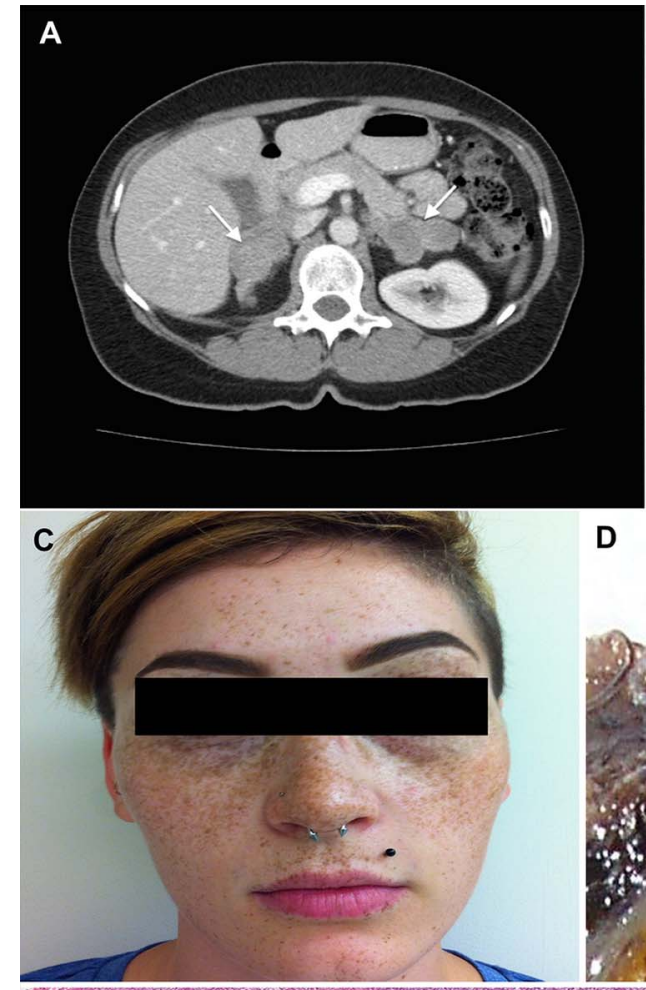

D
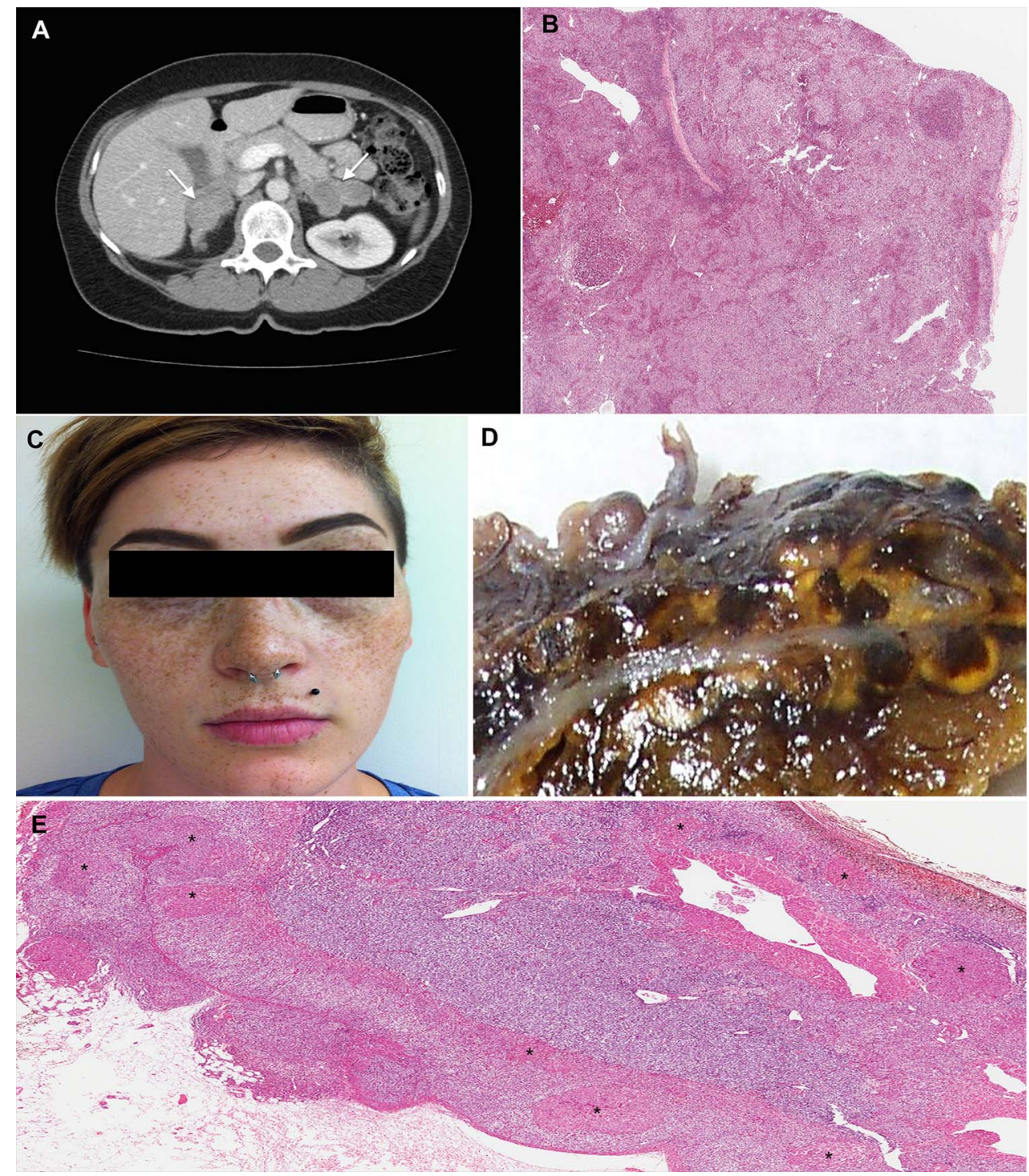

Figure 3 Nodular hyperplasia. Primary bilateral adrenocortical nodular hyperplasia is classified as either macronodular (nodules $>1 \mathrm{~cm}$ ) or micronodular (nodules $<1 \mathrm{~cm}$ ), although a degree of morphological overlap may occur. CT shows adrenal glands with primary bilateral macronodular adrenocortical hyperplasia (A). In primary bilateral macronodular adrenocortical hyperplasia, the external surface of the glands is often 'bosselated' in appearance. Cross-section of the gland often reveals uncapsulated yellow to golden-yellow nodules ranging from $1 \mathrm{~cm}$ to $5 \mathrm{~cm}$ with irregular light-brown foci. Microscopically, the cells are pale, lipid-rich and contain vacuolated cytoplasm, admixed with compact cells (B). The micronodular subtype presents a pigmented form 'primary pigmented adrenocortical disease (PPNAD)', and a scarcely/non-pigmented form 'micronodular adrenocortical disease (MAD)'. Recognition of the pigmented variant (PPNAD) has clinical implications because it has been associated with $60 \%$ of patients with Carney complex. Photograph of a woman with Carney complex. Multiple ephelides are seen including some in the lips, which is a typical site of pigmentation in patients with this disorder (C). On cross-section, a large number of yellow to brown-black micronodules may be seen, ranging from $0.1 \mathrm{~mm}$ to $0.3 \mathrm{~mm}$ in size (D). Microscopically, the nodules (asterisks) are round-oval, encapsulated, and commonly found deep within the zona reticularis or near the corticomedullary junction (E). 

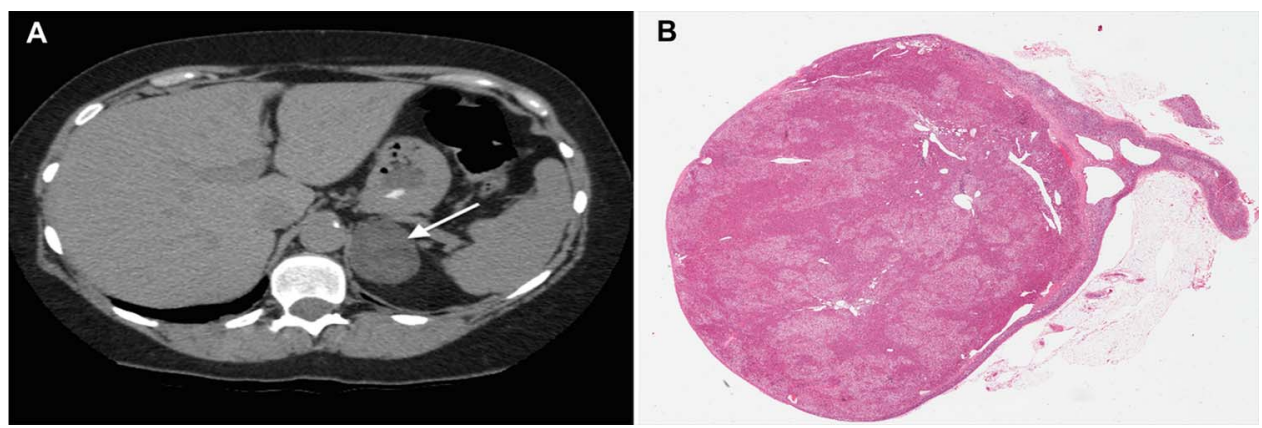

Figure 4 Adrenal cortical adenoma. CT shows sagittal and coronal views of a cortisol-producing adrenal adenoma (A). In cortisol-producing neoplasms, the non-tumorous cortex almost inevitably shows adrenal cortical atrophy due to negative feedback suppression effect of the hypothalamic-pituitary axis (B).

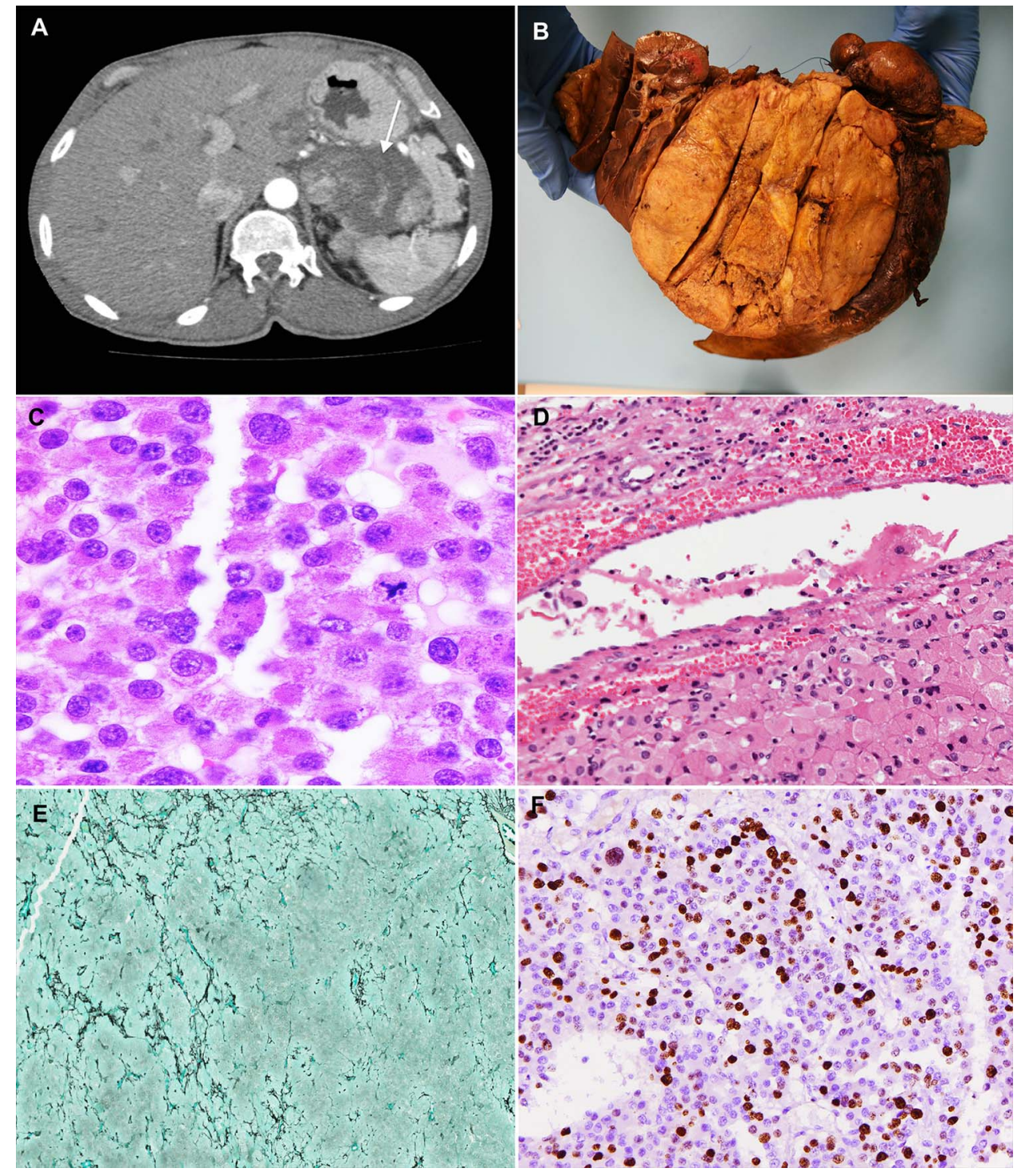

Figure 5 Adrenal cortical carcinoma. CT shows sagittal and coronal views of a cortisol-producing adrenocortical carcinoma (A). Grossly, adrenocortical carcinomas may weigh more than $100 \mathrm{~g}$, with measurements ranging from $3 \mathrm{~cm}$ to $40 \mathrm{~cm}$ (B). While some are encapsulated, many are adherent to or invade adjacent structures. On slicing, these tumours often reveal lobulation with fibrous bands and areas of necrosis and haemorrhage (B). Microscopically, adrenocortical carcinomas exhibit a more disorganised architecture than adenomas, with trabecular and diffuse patterns. Nuclear pleomorphism and increased mitoses ( $>5 / 50$ high power fields), including atypical mitotic figures (C), are frequently seen with capsular and vascular invasion. Vascular invasion is diagnosed when intravascular tumour cells adherent to thrombus is identified (D). A recently described novel approach using a 'reticulin algorithm', which has been shown to have high interobserver reproducibility. ${ }^{60-62}$ In this method, malignancy is suggested by an altered reticulin framework $(E)$ along with one of the following parameters: high mitotic rate ( $>5$ mitoses per 50 high power fields), vascular invasion and necrosis. Moreover, insulin-like growth factor 2 (IGF2) and p53 overexpression (F), along with a high Ki-67 $(>5 \%)$ have been described to be effective in differentiating carcinoma from adenoma. 


\section{Diffuse hyperplasia}

Diffuse bilateral adrenocortical hyperplasia is seen in ACTH-dependent Cushing's syndrome (figure 2B), in response to excess pituitary or ectopic ACTH production, and very rarely ectopic CRH production. ${ }^{16}{ }^{34}$ In late stages, a mixed diffuse and nodular adrenocortical hyperplasia has been described. ${ }^{34}$ In Cushing's disease, the spectrum of pituitary ACTH-producing adenomas includes densely or sparsely granulated corticotroph adenoma and Crooke's cell adenoma (table 1). ${ }^{40-42}$ Clinically, an inverse correlation between pituitary tumour size and symptomatology has been reported. ${ }^{41}{ }^{42}$ Densely granulated corticotroph adenomas are usually described as microadenomas $(<1 \mathrm{~cm})$ causing the more florid Cushing presentation, whereas sparsely granulated corticotroph adenomas and Crooke's cell adenomas are often described as macroadenomas $(>1 \mathrm{~cm})$ presenting with subclinical Cushing features. ${ }^{41} 42$ The pathological assessment of Crooke's hyaline change in non-tumorous corticotrophs is clinically pertinent: if absent, the risk of recurrence after resection of a corticotroph adenoma is typically higher. $^{4142}$

\section{Nodular hyperplasia}

Primary bilateral adrenocortical nodular hyperplasia accounts for an estimated $10 \%$ of cases of adrenal Cushing's syndrome (figure 3). ${ }^{11-12}{ }^{16}{ }^{34}$ It is classified as either macronodular (nodules $>1 \mathrm{~cm}$ ) or micronodular (nodules $<1 \mathrm{~cm}$ ), although a degree of morphological overlap may occur. ${ }^{11-13} 1634$

The macronodular subtype, previously known as ACTH-independent macronodular adrenocortical hyperplasia, has been recently redefined as primary bilateral macronodular adrenocortical hyperplasia (BMAH) due to the discovery of intra-adrenal production of ACTH in this lesion (tables 2 and 3). ${ }^{11-13} 43-45$ Clinically, BMAH has a slight male predominance, and tends to present in the fifth to sixth decade of life with subclinical Cushing's syndrome (table 2). ${ }^{11-13}$ However, a variant (c-BMAH; childhood BMAH) associated with McCune-Albright syndrome has been reported, arising in early childhood with more florid Cushing's syndrome presentation. ${ }^{6}{ }^{11-13}$ Grossly, the adrenal glands appear enlarged and distorted, with a combined weight of 60-200 g. ${ }^{11} 131634$ The external surface of the glands is often 'bosselated' in appearance. Cross-section of the gland reveals uncapsulated yellow to golden-yellow nodules ranging from $1 \mathrm{~cm}$ to $5 \mathrm{~cm}$ with irregular light-brown foci. ${ }^{11} 1316{ }^{34}$ Microscopically, the cells are pale, lipid-rich and contain vacuolated cytoplasm, admixed with rare compact cells containing strong eosinophilic cytoplasm (figure 3B). Minimal nuclear pleomorphism and rare mitotic figures are seen. The internodular cortex may be either hyperplastic or atrophic. ${ }^{11} 13$ Although this distinction is not well understood, the internodular cortical atrophy has been described in the McCune-Albright associated variant of BMAH (c-BMAH). ${ }^{11} 13$

The micronodular subtype presents a pigmented form 'primary pigmented adrenocortical disease (PPNAD)', and a scarcely/non-pigmented form 'micronodular adrenocortical disease (MAD)', although considerable clinical, morphological and genetic overlap is seen between the two groups (tables 2 and 3). ${ }^{11-13} 344^{46-49}$ Clinically, PPNAD and MAD have a slight female predominance; they also tend to arise at a younger age and with more florid Cushing features than BMAH. Biochemically, a paradoxical increase in the 6-day Liddle's dexamethasone suppression test has been described, which is thought to be correlated with glucocorticoid-receptor overexpression in the pigmented micronodules. ${ }^{50}$ Recognition of the pigmented variant (PPNAD) has clinical implications because it has been associated with $60 \%$ of patients with Carney complex (CNC, figure 3C), in which case echocardiography is warranted to rule out a potentially fatal cardiac myxoma. ${ }^{13} \quad 25 \quad 2649$ Grossly, adrenocortical micronodular hyperplasia presents with normal to slightly enlarged adrenal glands, with a combined weight of 4.3-17.0 g. ${ }^{11} 12 \quad 1634$ On cross-section, a large number of yellow to brown-black micronodules may be seen, ranging from $0.1 \mathrm{~mm}$ to $0.3 \mathrm{~mm}$ in size (figure $3 \mathrm{D}$ ). The pigmented appearance is a result of lipofuscin storage within the nodules (figure 3E). Microscopically, the nodules are roundoval, encapsulated, and commonly found deep within the zona reticularis or near the corticomedullary junction (figure 3D). ${ }^{34}$ The cells often show compact eosinophilic cytoplasm, although rare cells with lipid-rich and vacuolated cytoplasm may be seen. ${ }^{34}$ Mitotic figures are seldom present. ${ }^{34}$

The ancillary features of cortisol-producing adrenocortical nodular hyperplasia provide some clues as to why the macronodular subtype, despite massive adrenal enlargement, offer relatively inefficient cortisol overproduction in comparison with the normal-sized micronodular glands. Ultrastructural studies of macronodules often show poorly developed smooth endoplasmic reticulum in the large pale lipid-rich cortical cells, alongside weak reactivity for $3 \beta$-hydroxysteroid dehydrogenase and other enzymes involved in steroidogenesis. ${ }^{34}$ By contrast, cortical cells within smaller micronodules often show intense activity for steroidogenic enzymes. On ultrastructural studies, these cells show compact eosinophilic cytoplasm, with significantly more developed smooth endoplasmic reticulum. ${ }^{34}$

\section{Adrenocortical neoplasms}

Unilateral adrenocortical neoplasms account for 90\% of cases of adrenal Cushing's syndrome. ${ }^{2-4}{ }^{8-12}$ In these circumstances, the pathological assessment of the non-tumorous cortex is important to determine the functional status of the tumour. In cortisol-producing neoplasms, the non-tumorous cortex almost inevitably shows some degree of adrenal cortical atrophy due to negative feedback suppression effect of the hypothalamicpituitary axis (figure 4B). In contrast, the non-tumorous cortex of non-functioning and aldosterone-producing adrenal cortical neoplasms is not atrophic. In aldosterone-producing neoplasms, the zona glomerulosa may even exhibit hyperplasia, the so-called 'paradoxical hyperplasia'. 16283451

In surgical series, adrenocortical adenoma is the most common adrenal presentation of Cushing's syndrome (figure 4), accounting for nearly 55\% of cases (tables 2 and 3)..$^{2-4} 111216$ Clinically, these tumours can arise at any age, with a slight female predominance. ${ }^{11}{ }^{12}$ The presentation ranges from subclinical to overt Cushing. ${ }^{11} 12{ }^{34}$ Smaller size adenomas, harbouring mutations in PRKACA and GNAS, have been reported with earlier onset and more overt hypercortisolism. ${ }^{52}$ Grossly, cortisol-producing adenomas are described as solitary, round-to-ovoid neoplasms, ranging from $1.5 \mathrm{~cm}$ to $6 \mathrm{~cm}$ in size, and weighing between $10 \mathrm{~g}$ and $40 \mathrm{~g} .{ }^{16}{ }^{34-37}$ On cross-section, the tumour is typically homogenous yellow or golden-yellow, with occasional foci of dark discolouration. ${ }^{16}{ }^{34}$ Rare cases of pigmented 'black' adenomas have been reported, with a similar clinical course as their non-pigmented counterparts. ${ }^{16}{ }^{34}$ Microscopically, the neoplastic cells tend to be pale-staining, lipid-rich, with uniform round-oval nuclei and clear cytoplasm. ${ }^{16}$ 34-37 Common architectural patterns include nesting-alveolar, short cords, narrow interconnecting trabecular or a mixture of these patterns within the same tumour. ${ }^{34}$ Mitotic figures are rarely present. ${ }^{34-37}$ On electron microscopy, 
cortisol-producing adenomas contain mitochondria with tubular or vesicular cristae, which are quite distinct from the lamellar type or plate-like cristae seen in aldosterone-producing adenomas. $^{28} 3451$

In contrast to adenomas, adrenocortical carcinomas are quite rare and account for $35 \%$ of cases of adrenal Cushing's syndrome (tables 2 and 3). ${ }^{2-4} 11121647$ Clinically, they can present at any age depending on whether they arise sporadically or in the setting of familial syndromes. ${ }^{11} 12$ 53-58 The more common sporadic cases tend to present in the fourth to fifth decade of life with a female predominance, aggressive onset of hypercortisolism, overt Cushing's syndrome features and occasionally concurrent virilisation symptoms. ${ }^{11} 12 \quad 53-57$ Grossly, adrenocortical carcinomas may weigh more than $100 \mathrm{~g}$, with measurements ranging from $3 \mathrm{~cm}$ to $40 \mathrm{~cm}^{16} 2834-3859$ While some are encapsulated, many are adherent to or invade adjacent structures. On slicing, these tumours often reveal lobulation with fibrous bands and areas of necrosis and haemorrhage (figure 5B). Microscopically, adrenocortical carcinomas exhibit a more disorganised architecture than adenomas, with trabecular and diffuse patterns. ${ }^{34-38} 59$ Nuclear pleomorphism and increased mitoses ( $>5 / 50$ high power fields), including atypical mitotic figures (figure 5C), are frequently seen with capsular and vascular invasion in the vast majority of high-grade adrenocortical carcinomas. ${ }^{28}$ 34-38

While the morphological features of 'florid' adrenal cortical carcinomas are quite different from typical benign adenomas, the distinction between a non-invasive low-grade carcinoma and an adenoma with atypical features can be challenging in some cases. $^{28} 58 \quad 60$ Even the commonly used Weiss scoring system carries significant interobserver variability, along with diagnostic uncertainty when an adrenal cortical neoplasm receives an intermediate score of 2 or $3 .^{285860}$ Recently, Volante et al described a novel approach using a 'reticulin algorithm', which has been shown to have high interobserver reproducibility. ${ }^{60-62}$ In this method, malignancy is suggested by an altered reticulin framework (figure 5D) along with one of the following parameters: high mitotic rate ( $>5$ mitoses per 50 high power fields), vascular invasion and necrosis. ${ }^{58}$ 60-62 Moreover, IGF2 and p53 overexpression, along with a high Ki-67 (>5\%) have been described to be effective in differentiating carcinoma from adenoma. ${ }^{28} \quad 34-38 \quad 58$ Recent transcriptome analysis highlighted that adrenal cortical carcinomas can be distinguished clearly from adenomas slightly better than morphological assessment based on gene expression profile of an adrenal cortical neoplasm. ${ }^{54} 58$ Moreover, DNA microarray analysis of a large group of adrenocortical tumours divided the malignant tumours into two groups and provided prognostic information independent of tumour mitotic rate and stage. ${ }^{54} 5863$ While the combined expression of BUB1B and PINK1 provided overall the best prediction of overall survival, the combined expression of DLG7 and PINK1 was found to be the best predictor of disease-free survival. ${ }^{63}$ Occasionally, when there is a need to differentiate between a primary or metastatic adrenocortical tumour, the adrenocortical origin can be demonstrated by positive staining of markers of adrenal cortical cytodifferentiation, which includes steroidogenic factor-1, Melan-A (clone A103), calretinin, synaptophysin and $\alpha$-inhibin. ${ }^{28} \quad 34-3858$

\section{PATHOGENESIS AND MOLECULAR FEATURES OF ADRENAL} CUSHING'S SYNDROME

Over the last decade, significant advances made in molecular pathology have enhanced our understanding of Cushing's syndrome (figure 6). Recent application of whole-genome

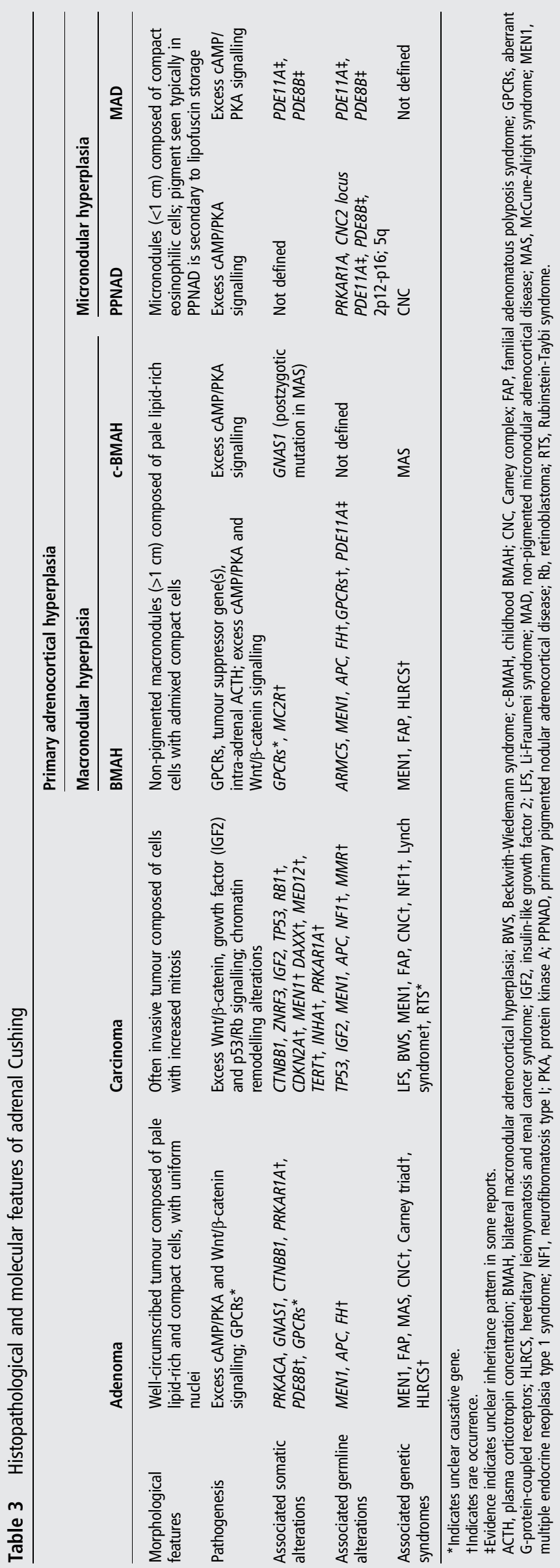


sequencing techniques have allowed the discovery of somatic and germline mutations implicated in the pathogenesis of primary cortisol-producing adrenocortical lesions. ${ }^{52}$ 64-72 Most of these mutations (PRKACA, PRKAR1A, GNAS, PDE11A, $P D E 8 B)$ cause aberrant activation of the cyclic AMP (cAMP)-signalling pathway, resulting in hormone overproduction and cellular proliferation (figure 6). ${ }^{11-13} \quad 52 \quad 64-81$ Other mutations involve pathways associated with 'neoplastic transformation', favouring tumour growth over hormone overproduction. $^{70}$ These include mutations in armadillo repeat containing 5 gene (ARMC5) a putative tumour suppressor gene, Wnt/ß-catenin pathway (CTNNB1, ZNRF3), growth factor overexpression (IGF2), p53/retinoblastoma protein pathway (TP53, CDKN2A, RB1) and chromatin remodelling (MEN1, DAXX). ${ }^{11-13} 39565882-91$

\section{Normal physiology of adrenal cortisol secretion}

In normal physiology, cortisol secretion is under the control of the hypothalamic-pituitary-adrenal axis (figure 6A). ${ }^{12} \quad 52 \quad 64-70$ Under stress, the hypothalamus releases $\mathrm{CRH}$, which result in ACTH secretion from the anterior pituitary gland. ACTH binds to melanocortin-2 receptor, a G-protein-coupled receptor in the adrenal fasciculata cells, causing activation of adenylyl cyclase through Gs- $\alpha$ subunit, and generating cAMP (figure 6B). ${ }^{12} 52 \quad 64-70$ The cAMP then binds the regulatory subunit of protein kinase A, causing release of the PKA catalytic subunit (PKA-C). This results in phosphorylation of downstream targets, including cAMP response element-binding protein, which induces cortisol biosynthesis and proliferation of the adrenal cortex. ${ }^{52}$ After the stimulus finishes, cAMP is hydrolysed by phosphodiesterase and the PKA subunit is reassembled again, returning to its inactive state. ${ }^{12} 52$ 64-70

\section{Primary adrenocortical hyperplasia}

The role of aberrant cAMP signalling (figure 6C) in autonomous adrenal cortisol production was initially described in primary adrenocortical nodular hyperplasia. Recent genetic analyses of these lesions have revealed distinct mutations implicated in the pathogenesis of macronodular and micronodular subtypes (table 3). ${ }^{411-13274964}$

Historically, the macronodular subtype, also known as primary BMAH, was thought to be mainly sporadic due to aberrancies in the cAMP signalling pathway. ${ }^{4}$ 11-13 2792 Cases with aberrant $G$ protein-coupled membrane receptor (GPCR) response to a variety of hormones (vasopressin, serotonin, gastric inhibitory polypeptide, catecholamines, luteinising hormone/human chorionic gonadotropin, angiotensin) are well described in the literature. ${ }^{13} 9293$ Rare activating mutations in melanocortin-2 receptor have also been reported. ${ }^{1-13} \mathrm{c}-\mathrm{BMAH}$ has been linked to a postzygotic activating mutation (somatic mosaicism) in the GNAS gene which encodes the Go subunit in the cAMP pathway; c-BMAH occurs frequently in the setting of McCune-Albright syndrome but may also present in an isolated manner. $^{11-1327}$

Over the past year, our knowledge of BMAH has greatly evolved. The recent discovery of inactivating germline mutations (ARMC5) in over $50 \%$ of cases suggests that this disease is much more hereditary than previously thought. ${ }^{70}{ }^{82-86}$ Mutations in the ARMC5 putative tumour suppressor gene has been shown to cause altered cell survival and decreased steroidogenesis, favouring the hypothesis of tumour growth over hormone production in the pathogenesis of BMAH. ${ }^{82-86}$ This is consistent with its common clinical presentation where relatively inefficient cortisol overproduction is seen despite massive adrenal enlargement. $^{13} 276982-86$ Very recently, a case of BMAH with ARMC5 mutation has also been described with concomitant intracranial meningiomas, raising the possibility of a new tumour syndrome. ${ }^{94}$ Other inherited cases have been reported in the setting multiple endocrine neoplasia type 1 syndrome (MEN1 gene), familial adenomatous polyposis (FAP) syndrome (APC gene), hereditary leiomyomatosis and renal cancer syndrome ( $F H$ gene), as well as familial alterations in cAMP signalling (familial GPCRs and PDE11A gene). ${ }^{11-13} 27$ Finally, recent studies have also shown that BMAH, traditionally thought to be ACTH-independent, is at least partially regulated by intra-adrenal production of ACTH. ${ }^{43-458286}$

The micronodular subtype is mainly hereditary in nature, although rare sporadic cases have also been reported (table 3). ${ }^{11-13} 46-49$ The densely pigmented variant, known as PPNAD, typically occurs in the setting of Carney complex (c-PPNAD) and rarely in isolated cases (i-PPNAD). The pathogenesis of c-PPNAD has been attributed predominantly (up to $73 \%$ ) to an inactivating germline mutation in PRKAR1A gene, which encodes the regulatory subunit of protein kinase A, and in rare circumstance to alterations of the CNC2 gene locus. ${ }^{11-13}$ 46-49 64 The pathogenesis of i-PPNAD has been linked to inactivating mutations in PRKAR1A, as well as rare alterations in phosphodiesterase genes (PDE11A, PDE8B) and 2 p16. ${ }^{11} 1249$ Cases of scarcely or non-pigmented primary micronodular hyperplasia (MAD) have been associated with inactivating mutations in PDE genes (PDE11A, PDE8B), as well as alterations of 2p12-p16 and 5q. ${ }^{11} 12498081$

\section{Cortisol-producing neoplasms}

Contrary to the inherited nature of primary cortisol-producing adrenocortical hyperplasia, cortisol-producing adrenocortical neoplasms often arise sporadically (table 3). Rare cases of adrenocortical adenoma have been reported in the setting of multiple endocrine neoplasia type 1 syndrome (MEN1), FAP syndrome, McCune-Albright syndrome, CNC, Carney triad and hereditary leiomyomatosis and renal cancer syndrome. ${ }^{11} 125695$ Moreover, cases of adrenocortical carcinoma have been reported in association with cancer susceptibility syndromes (Li-Fraumeni syndrome (TP53 gene), Beckwith-Wiedemann syndrome (alteration of 11p15.5; IGF2), MEN1, FAP, Lynch syndrome, neurofibromatosis type 1 syndrome) and CNC. ${ }^{11} \quad 12 \quad 47 \quad 53-58$ A rare Brazil variant of adrenocortical carcinoma, involving a specific germline TP53 mutation $(\mathrm{R} 337 \mathrm{H})$, has been described, arising in early childhood. ${ }^{11} 1253-58$

The pathogenesis of sporadic cortisol-producing adrenocortical adenomas has remained largely unknown until earlier this year when six independent studies consecutively reported somatic activating mutations in the catalytic subunit of PKA (PRKACA gene) in $35-69 \%$ of cases. ${ }^{52}$ 64-72 Based on crystal structure studies of PKA, the mutation is proposed to disrupt the interface between catalytic (PKA-C) and regulatory subunits. ${ }^{64-72}$ This disruption results in unregulated PKA-C activity, which causes PKA hyperactivation and cortisol overproduction. $^{52}$ 64-72 Somatic activating mutations in the GNAS gene have also been reported in $5-17 \%$ of cases of adenomas. ${ }^{52}{ }^{67} \mathrm{In}$ contrast with PRKACA and GNAS mutations causing aberrant cAMP/PKA signalling, the other frequently reported mutation in cortisol-producing adenomas involves the CTNBB1 gene (16\%), which results in excess $\mathrm{Wnt} / \beta$-catenin signalling. ${ }^{39}{ }^{52}$ Interestingly, aberrant activation of the $\mathrm{Wnt} / \beta$-catenin pathway has also been reported in $70 \%$ of aldosterone-producing adrenocortical adenomas. ${ }^{28} 96$ In a recent study, mutations in PRKACA, GNAS and CTNBB1 appeared to be mutually 
Figure 6 Molecular biological features of adrenal Cushing. In normal physiology, cortisol secretion in adrenal zona fasciculata (ZF) cells is mediated by the CAMP/protein kinase A (PKA) signalling pathway. In the resting state, protein kinase $A$ exists as an inactive tetramer, with the catalytic subunits (PKA-C) bound to regulatory subunits (PKA-R) (A). Under stress, the pituitary gland secretes corticotropin (ACTH), which binds to melanocortin receptor 2 (MC2R) on the ZF cells, causing activation of adenylyl cyclase through stimulatory G-protein $\alpha$ subunit $(\mathrm{Gs} \alpha)$, generating cyclic AMP (CAMP) from ATP (B). The cAMP then binds PKA-R, causing release of PKA-C. This results in phosphorylation of downstream targets, including CAMP response element-binding protein (CREB), which induces cortisol biosynthesis and proliferation of ZF cells. After the stimulus finishes, CAMP is hydrolysed by phosphodiesterase (PDE) and the PKA subunit is reassembled again, returning to its inactive state. In adrenal Cushing, somatic and germline mutations may arise at various steps of the cAMP/PKA pathway, causing excess signalling and resultant cortisol overproduction and secretion. These include activating mutations in PKA-C (PRKACA), PKA-R (PRKA1A), Gs $\alpha$ (GNAS), MC2R (MCR2), inactivating mutations in PDEs (PDE11A and $P D E 8 B)$ and ectopic/aberrant G-protein-coupled receptors (C).
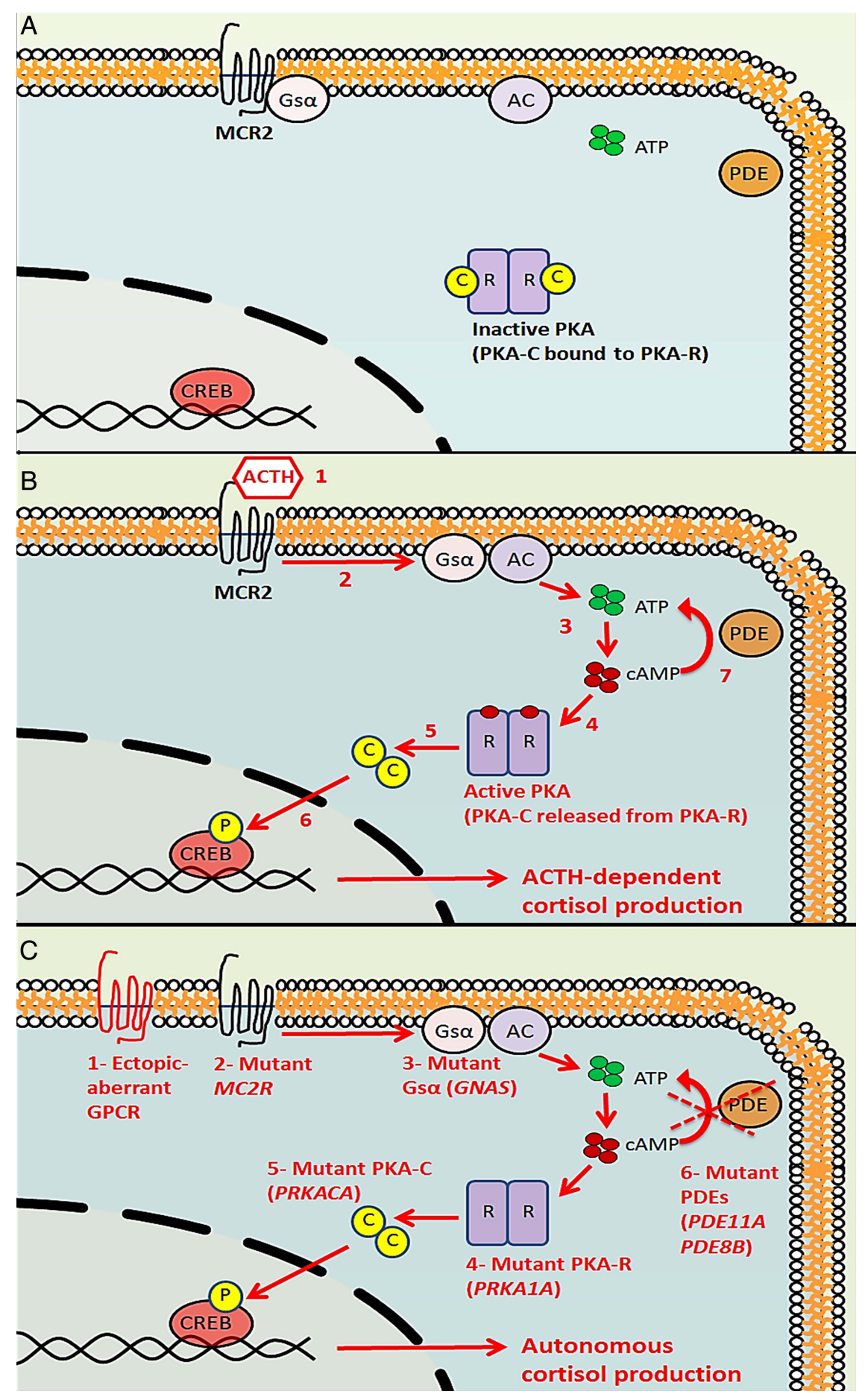

exclusive, which might explain the distinct genotype-phenotype correlations seen in cortisol-producing adenomas. ${ }^{52}$ Adenomas harbouring mutations in the cAMP pathway (PRKACA and GNAS) are generally smaller in size and present with more overt hypercortisolism than those harbouring mutations in the Wnt/ B-catenin pathway (CTNBB1). ${ }^{52}$ Rare cases of sporadic cortisolproducing adenomas have also been reported with alterations in PRKAR1A, PDE8B, and G protein-coupled receptors. ${ }^{11} 12$

In contrast with sporadic cortisol-producing adenomas, alterations in the cAMP pathway are scarcely reported in sporadic cortisol-producing adrenocortical carcinoma (table 3). ${ }^{11} 12$ The most frequently reported molecular alterations in adrenocortical carcinoma relate to 'tumorigenesis' pathways involving cellular proliferation, differentiation, survival and/or apoptosis. ${ }^{39} 70$ These include aberrant Wnt/B-catenin signalling (CTNNB1 and ZNRF3 gene mutations), insulin-like growth factor 2 (IGF2), p53/retinoblastoma protein signalling (TP53, CDKN2A and RB1 gene mutations), chromatin remodelling (MEN1 and DAXX) as well as alterations in MED12 and TERT. Rare sporadic carcinomas have also been reported with alterations in PRKAR1A. ${ }^{11} 1253-58879097$

The topic of precursor lesions in adrenal neoplasms remains an area of controversy. ${ }^{46} 98$ In contrast with other solid tumours such as in colon cancer, the frequently seen hyperplasia- 
adenoma-carcinoma sequence has not been clarified in the adrenal cortex. ${ }^{58} 9899$ Cases of adrenocortical adenomas and carcinomas arising in a background of hyperplasia have been frequently described in genetic syndromes (CNC, McCuneAlbright syndrome, MEN1, FAP). ${ }^{46}{ }^{47}$ Moreover, aberrancies in $\mathrm{Wnt} / \beta$-catenin signalling are increasingly reported in the development of hyperplasia and subsequent adrenocortical adenomas and carcinomas. ${ }^{28} 39465899$ Recently, Ronchi et al ${ }^{99}$ provided the first genome-wide high-resolution study of chromosomal changes in a large series of adrenocortical tumours. ${ }^{58}$ They discovered that malignant tumours carry more genetic aberrations than benign ones, and over $70 \%$ of the most frequent genetic alterations (small isolated copy number gains) found in adenomas were also present in carcinoma, supporting the hypothesis of a common early molecular signature. These data suggest that there is likely a subset of adrenocortical carcinoma that arises in the background of adrenocortical adenoma and hyperplasia.

\section{TREATMENT AND PROGNOSIS}

The management of endogenous Cushing's syndrome is mainly surgical and tailored to its primary aetiology. ${ }^{2-4}{ }^{11-15}$ In ACTH-dependent Cushing's syndrome, first-line treatment modalities include transsphenoidal pituitary adenomectomy and ectopic corticotroph tumour resection. ${ }^{14}{ }^{15}$ Second-line treatment is necessary when tumour resection is not possible or not curative. The pituitary gland may be addressed with radiation therapy and/or medical therapy using a dopamine agonist (cabergoline), or a somatostatin receptor agonist (pasireotide). ${ }^{100} 101$ Other options for controlling endogenous glucocorticoid excess include targeting of the adrenal gland via bilateral adrenalectomy or the use of steroidogenesis inhibitors (ketoconazole, metyrapone, mitotane, etomidate). Finally, the peripheral action of cortisol may be antagonised with mifepristone. ${ }^{102}$ Adrenalectomy is seldom used in ACTH-dependent Cushing because of the risk of Nelson's syndrome and lifelong adrenal replacement therapy. ${ }^{14}{ }^{15}$ In contrast, the treatment of choice for ACTH-independent Cushing's syndrome is laparoscopic adrenalectomy. ${ }^{2-4} 11 \quad 1320$ Bilateral adrenalectomy is recommended for adrenocortical micronodular and macronodular hyperplasia, while solitary cortisol-producing adrenocortical neoplasms are typically treated with unilateral adrenalectomy. ${ }^{3} 1125$ Perioperative adrenal supplementation is often necessary to avoid Addisonian crisis, a potentially fatal complication. ${ }^{3}{ }^{20}$ In BMAH, medical therapy may be attempted prior to surgery using steroidogenesis inhibitors or specific GPCR therapy ( $\beta$-blocker, GnRH analogue, somatostatin agonist), and unilateral adrenalectomy has been proposed in milder cases. ${ }^{13}$ The use of laparoscopic techniques remains controversial in suspected cases of adrenocortical carcinoma, and many institutions recommend open surgery. ${ }^{11} 545520$ There is ongoing debate regarding the indications for adjuvant mitotane therapy. Most investigators recommend it after incomplete resection of the adrenal carcinoma or in cases in which the carcinoma has a high proliferation (Ki67>10\% or mitotic rate $>20$ per 50 high-power fields)..$^{54} 55103$ Germline testing of p53 mutation is currently recommended in all patients diagnosed with adrenocortical carcinoma. ${ }^{47} 54104$

\section{CONCLUSIONS}

Over the past year, important milestones in the understanding of endocrine disorders and tumorigenesis have been achieved through genomic sequencing of adrenal cortical tumours. Concurrent to the discovery of mutations (KCNJ5, ATP1A1, $A T P 2 B 3, C A C N A 1 D)$ in the calcium/calmodulin kinase pathway causing primary aldosteronism, ${ }^{28} 105$ somatic and germline mutations (PRKACA, PRKAR1A, GNAS, PDE11A, PDE8B) discovered in the cAMP/PKApathway is now known to cause most cases of primary adrenal hypercortisolism. Despite emerging evidence of aberrant $\mathrm{Wnt} / \beta$-catenin signalling in the development of adrenocortical hyperplasia and neoplasms, the frequently seen hyperplasia-adenoma-carcinoma progression sequence remains to be determined in the adrenal cortex. Further clarification of these molecular biological features is critical to better classify and understand the genotype-phenotype correlates in adrenal Cushing's syndrome. Pathological correlates include adrenocortical hyperplasia, adenoma and carcinoma. In conjunction with careful consideration of clinical, biochemical and radiological findings, a thorough pathological assessment is currently the gold standard for subtyping and management of Cushing's syndrome.

\section{Take home messages}

- Accurate subtyping of Cushing's syndrome is essential for treatment decision-making and requires a complete integration of clinical, biochemical, radiological and pathological findings.

- Pathological correlations of Cushing's syndrome in the adrenal glands include adrenal cortical hyperplasia (diffuse and nodular), adenoma and carcinoma.

- Somatic and germline alterations in the CAMP/PKApathway is now known to cause most cases of primary adrenal hypercortisolism.

- In cortisol-producing adrenal cortical neoplasms, the nontumorous cortex almost inevitably shows adrenal cortical atrophy due to negative feedback suppression effect of the hypothalamic-pituitary axis.

- The diagnosis of adrenal cortical carcinoma is suggested by an altered reticulin framework along with one of the following parameters: high mitotic rate ( $>5$ mitoses per 50 high power fields), vascular invasion and necrosis.

- IGF2 and p53 overexpression, along with a high Ki-67 $(>5 \%)$ have also been described to be effective in differentiating adrenal cortical carcinoma from adenoma.

- Transcriptome profile of an adrenal cortical neoplasm distinguishes carcinoma from adenoma and provides prognostic information in a definite carcinoma.

Contributors OM: substantial contributions to the conception or design of the work; or the acquisition, analysis, or interpretation of data for the work; final approval of the version to be published; agreement to be accountable for all aspects of the work in ensuring that questions related to the accuracy or integrity of any part of the work are appropriately investigated and resolved. $\mathrm{KD}, \mathrm{KGH}$ and $\mathrm{OM}$ : drafting the work or revising it critically for important intellectual content.

Competing interests None.

Patient consent Obtained.

Provenance and peer review Not commissioned; externally peer reviewed.

\section{REFERENCES}

1 Nieman LK, Biller BM, Findling JW, et al. The diagnosis of Cushing's syndrome: an Endocrine Society Clinical Practice Guideline. J Clin Endocrinol Metab 2008;93:1526-40.

2 Bertagna X, Guignat L, Groussin L, et al. Cushing's disease. Best Pract Res Clin Endocrinol Metab 2009;23:607-23.

3 Hatipoglu BA. Cushing's syndrome. J Surg Oncol 2012;106:565-71. 
4 Newell-price J, Bertagna X, Grossman AB, et al. Cushing's syndrome. Lancet 2006;367:1605-17.

5 Tabarin A, Perez P. Pros and cons of screening for occult Cushing syndrome. Nat Rev Endocrinol 2011;7:445-55.

6 Stratakis CA. Cushing syndrome in pediatrics. Endocrinol Metab Clin North Am 2012:41:793-803.

7 Clayton RN, Raskauskiene D, Reulen RC, et al. Mortality and morbidity in Cushing's disease over 50 years in Stoke-on-Trent, UK: audit and meta-analysis of literature. J Clin Endocrinol Metab 2011;96:632-42.

8 Carroll TB, Findling JW. Cushing's syndrome of nonpituitary causes. Curr Opin Endocrinol Diabetes Obes 2009;16:308-15.

9 Bourdeau I, Lampron A, Costa MH, et al. Adrenocorticotropic hormone-independent Cushing's syndrome. Curr Opin Endocrinol Diabetes Obes 2007; 14:219-25.

10 Shahani S, Nudelman RJ, Nalini R, et al. Ectopic corticotropin-releasing hormone (CRH) syndrome from metastatic small cell carcinoma: a case report and review of the literature. Diagn Pathol 2010;5:56.

11 Stratakis CA. Cushing syndrome caused by adrenocortical tumors and hyperplasias (corticotropin-independent Cushing syndrome). Endocr Dev 2008;13:117-32.

12 Stratakis CA, Boikos SA. Genetics of adrenal tumors associated with Cushing's syndrome: a new classification for bilateral adrenocortical hyperplasias. Nat Clin Pract Endocrinol Metab 2007;3:748-57.

13 De Venanzi A, Alencar GA, Bourdeau I, et al. Primary bilateral macronodular adrenal hyperplasia. Curr Opin Endocrinol Diabetes Obes 2014;21:177-84.

14 Biller BM, Grossman AB, Stewart PM, et al. Treatment of adrenocorticotropin-dependent Cushing's syndrome: a consensus statement. J Clin Endocrinol Metab 2008;93:2454-62.

15 Tritos NA, Biller BM, Swearingen B. Management of Cushing disease. Nat Rev Endocrinol 2011;7:279-89.

16 Sasano H. The adrenal cortex. In: Stefaneanu L, Sasano H, Kovacs K, eds. Molecular and cellular endocrine pathology. London: Arnold, 2000:221-52.

17 Cizza G, Nieman LK, Doppman JL, et al. Factitious Cushing syndrome. J Clin Endocrinol Metab 1996;81:3573-7.

18 Newell-price J, Trainer $\mathrm{P}$, Besser $\mathrm{M}$, et al. The diagnosis and differential diagnosis of Cushing's syndrome and pseudo-Cushing's states. Endocr Rev 1998;19:647-72.

19 Boscaro M, Arnaldi G. Approach to the patient with possible Cushing's syndrome. J Clin Endocrinol Metab 2009;94:3121-31.

20 Miller BS, Doherty GM. Surgical management of adrenocortical tumours. Nat Rev Endocrinol 2014;10:282-92.

21 Ilias I, Sahdev A, Reznek RH, et al. The optimal imaging of adrenal tumours: a comparison of different methods. Endocr Relat Cancer 2007:14:587-99.

22 Lattin GE, Sturgill ED, Tujo CA, et al. From the radiologic pathology archives: Adrenal tumors and tumor-like conditions in the adult: radiologic-pathologic correlation. Radiographics 2014;34:805-29.

23 Young WF. Clinical practice. The incidentally discovered adrenal mass. N Engl J Med 2007;356:601-10.

24 Rockall AG, Babar SA, Sohaib SA, et al. CT and MR imaging of the adrenal glands in ACTH-independent cushing syndrome. Radiographics 2004;24:435-52.

25 Powell AC, Stratakis CA, Patronas NJ, et al. Operative management of Cushing syndrome secondary to micronodular adrenal hyperplasia. Surgery 2008:143:750-8.

26 Courcoutsakis N, Prassopoulos P, Stratakis CA. CT findings of primary pigmented nodular adrenocortical disease: rare cause of ACTH-independent Cushing syndrome. AJR Am J Roentgenol 2010;194:W541.

27 Lacroix A. ACTH-independent macronodular adrenal hyperplasia. Best Pract Res Clin Endocrinol Metab 2009;23:245-59.

28 Duan K, Mete O. Clinicopathologic correlates of primary aldosteronism. Arch Pathol Lab Med. In press.

29 Zeiger MA, Thompson GB, Duh QY, et al. American Association of Clinical Endocrinologists and American Association of Endocrine Surgeons Medical Guidelines for the Management of Adrenal Incidentalomas: executive summary of recommendations. Endocr Pract 2009;15:450-3.

30 Terzolo M, Stigliano A, Chiodini I, et al. AME position statement on adrenal incidentaloma. Eur J Endocrinol 2011;164:851-70.

31 Kannan S, Remer EM, Hamrahian AH. Evaluation of patients with adrenal incidentalomas. Curr Opin Endocrinol Diabetes Obes 2013;20:161-9.

32 Arnaldi G, Boscaro M. Adrenal incidentaloma. Best Pract Res Clin Endocrinol Metab 2012;26:405-19.

33 Funder J, Carey R, Fardella C, et al. Case detection, diagnosis, and treatment of patients with primary aldosteronism: an Endocrine Society clinical practice guideline. J Clin Endocrinol Metab 2008;93:3266-81.

34 Lack EE. AFIP atlas of tumor pathology, fourth series, fascicle 8. Tumors of the adrenal glands and extraadrenal paraganglia. Washington, DC: ARP Press, 2007.

35 Mcnicol AM. Diagnostic and molecular aspects of adrenal cortical tumors. Semin Diagn Pathol 2013;30:197-206.

36 Mcnicol AM. Update on tumours of the adrenal cortex, phaeochromocytoma and extra-adrenal paraganglioma. Histopathology 2011;58:155-68.
37 Mcnicol AM. Lesions of the adrenal cortex. Arch Pathol Lab Med 2008;132:1263-71.

38 Mcnicol AM. A diagnostic approach to adrenal cortical lesions. Endocr Pathol 2008; 19:241-51.

39 Berthon A, Martinez A, Bertherat J, et al. Wnt/ß-catenin signalling in adrenal physiology and tumour development. Mol Cell Endocrinol 2012;351:87-95.

40 Xekouki P, Azevedo M, Stratakis CA. Anterior pituitary adenomas: inherited syndromes, novel genes and molecular pathways. Expert Rev Endocrinol Metab 2010;5:697-709.

41 Mete 0, Asa SL. Clinicopathological correlations in pituitary adenomas. Brain Pathol 2012;22:443-53.

42 Mete 0 , Asa SL. Therapeutic implications of accurate classification of pituitary adenomas. Semin Diagn Pathol 2013:30:158-64.

43 Louiset E, Duparc C, Young J, et al. Intraadrenal corticotropin in bilateral macronodular adrenal hyperplasia. N Engl J Med 2013;369:2115-25.

44 Nishikawa T, Iwata M, Sasano H. Intraadrenal corticotropin in bilateral macronodular adrenal hyperplasia. N Engl J Med 2014;370:1071.

45 Lefebvre H, Duparc C, Chartrel N, et al. Intraadrenal adrenocorticotropin production in a case of bilateral macronodular adrenal hyperplasia causing Cushing's syndrome. J Clin Endocrinol Metab 2003;88:3035-42.

46 Mete 0, Asa SL. Precursor lesions of endocrine system neoplasms. Pathology 2013:45:316-30.

47 Morin E, Mete O, Wasserman JD, et al. Carney complex with adrenal cortical carcinoma. J Clin Endocrinol Metab 2012;97:E202-6.

48 Carney JA, Libé R, Bertherat J, et al. Primary pigmented nodular adrenocortical disease: the original 4 cases revisited after 30 years for follow-up, new investigations, and molecular genetic findings. Am J Surg Pathol 2014;38:1266-73.

49 Almeida MQ, Stratakis CA. Carney complex and other conditions associated with micronodular adrenal hyperplasias. Best Pract Res Clin Endocrinol Metab 2010:24:907-14.

50 Louiset E, Stratakis CA, Perraudin V, et al. The paradoxical increase in cortisol secretion induced by dexamethasone in primary pigmented nodular adrenocortical disease involves a glucocorticoid receptor-mediated effect of dexamethasone on protein kinase A catalytic subunits. J Clin Endocrinol Metab 2009;94:2406-13.

51 Mete 0, Asa SL. Morphological distinction of cortisol-producing and aldosterone-producing adrenal cortical adenomas: not only possible but a critical clinical responsibility. Histopathology 2012;60:1015-16.

52 Goh G, Scholl UI, Healy JM, et al. Recurrent activating mutation in PRKACA in cortisol-producing adrenal tumors. Nat Genet 2014;46:613-17.

53 De Martino MC, Al Ghuzlan A, Aubert S, et al. Molecular screening for a personalized treatment approach in advanced adrenocortical cancer. J Clin Endocrinol Metab 2013;98:4080-108.

54 Bourdeau I, Mackenzie-feder J, Lacroix A. Recent advances in adrenocortical carcinoma in adults. Curr Opin Endocrinol Diabetes Obes 2013;20:192-7.

55 Fassnacht M, Libé R, Kroiss M, et al. Adrenocortical carcinoma: a clinician's update. Nat Rev Endocrinol 2011;7:323-35.

56 Lerario AM, Moraitis A, Hammer GD. Genetics and epigenetics of adrenocortical tumors. Mol Cell Endocrinol 2014:386:67-84.

57 Lacroix A. Approach to the patient with adrenocortical carcinoma. J Clin Endocrinol Metab 2010;95:4812-22.

58 Papotti M, Duregon E, Volante $\mathrm{M}$, et al. Pathology of the adrenal cortex: a reappraisal of the past 25 years focusing on adrenal cortical tumors. Endocr Pathol 2014:25:35-48.

59 DeLellis RA, ed. Pathology \& genetics: tumours of endocrine organs. Vol. 8. IARC, 2004

60 Papotti $M$, Libè $R$, Duregon $E$, et al. The Weiss score and beyond-histopathology for adrenocortical carcinoma. Horm Cancer 2011;2:333-40.

61 Volante M, Bollito E, Sperone P, et al. Clinicopathological study of a series of 92 adrenocortical carcinomas: from a proposal of simplified diagnostic algorithm to prognostic stratification. Histopathology 2009;55:535-43.

62 Duregon E, Fassina A, Volante $M$, et al. The reticulin algorithm for adrenocortical tumor diagnosis: a multicentric validation study on 245 unpublished cases. Am J Surg Pathol 2013;37:1433-40.

63 De Reyniès A, Assié G, Rickman DS, et al. Gene expression profiling reveals a new classification of adrenocortical tumors and identifies molecular predictors of malignancy and survival. J Clin Oncol 2009;27:1108-15.

64 Espiard S, Ragazzon B, Bertherat J. Protein kinase A alterations in adrenocortical tumors. Horm Metab Res 2014.

65 Di Dalmazi G, Kisker C, Calebiro D, et al. Novel somatic mutations in the catalytic subunit of the protein kinase $A$ as a cause of adrenal Cushing's syndrome: a European multicentric study. J Clin Endocrinol Metab 2014;99:E2093-100.

66 Nakajima Y, Okamura T, Gohko T, et al. Somatic mutations of the catalytic subunit of cyclic AMP-dependent protein kinase (PRKACA) gene in Japanese patients with several adrenal adenomas secreting cortisol [Rapid Communication]. Endocr J 2014.

67 Sato $Y$, Maekawa $S$, Ishii $R$, et al. Recurrent somatic mutations underlie corticotropin-independent Cushing's syndrome. Science 2014;344:917-20.

68 Cao Y, He M, Gao Z, et al. Activating hotspot L205R mutation in PRKACA and adrenal Cushing's syndrome. Science 2014;344:913-17. 
69 Beuschlein F, Fassnacht M, Assié G, et al. Constitutive activation of PKA catalytic subunit in adrenal Cushing's syndrome. N Engl J Med 2014;370:1019-28.

70 Kirschner LS. Medicine. A unified cause for adrenal Cushing's syndrome. Science 2014;344:804-5.

71 Giordano TJ. Genetics: Pinpointing a hotspot in adrenal Cushing syndrome. Nat Rev Endocrinol 2014;10:447-8.

72 Sargent J. Neuroendocrine cancer. An activating hotspot mutation in PRKACA provides clues for adrenal Cushing syndrome therapeutics. Nat Rev Endocrinol 2014;10:311

73 De Joussineau C, Sahut-Barnola I, Levy I, et al. The CAMP pathway and the control of adrenocortical development and growth. Mol Cell Endocrinol 2012:351:28-36.

74 Yu B, Ragazzon B, Rizk-Rabin $\mathrm{M}$, et al. Protein kinase $\mathrm{A}$ alterations in endocrine tumors. Horm Metab Res 2012:44:741-8.

75 Wilmot Roussel H, Vezzosi D, Rizk-Rabin M, et al. Identification of gene expression profiles associated with cortisol secretion in adrenocortical adenomas. J Clin Endocrinol Metab 2013;98:E1109-21.

76 Kirschner LS, Carney JA, Pack SD, et al. Mutations of the gene encoding the protein kinase A type I-alpha regulatory subunit in patients with the Carney complex. Nat Genet 2000;26:89-92.

77 Azevedo MF, Faucz FR, Bimpaki E, et al. Clinical and molecular genetics of the phosphodiesterases (PDEs). Endocr Rev 2014;35:195-233.

78 Vezzosi D, Libé R, Baudry C, et al. Phosphodiesterase 11A (PDE11A) gene defects in patients with $\mathrm{ACTH}$-independent macronodular adrenal hyperplasia (AIMAH): functional variants may contribute to genetic susceptibility of bilateral adrenal tumors. J Clin Endocrinol Metab 2012;97:E2063-9.

79 Rothenbuhler A, Horvath A, Libé $R$, et al. Identification of novel genetic variants in phosphodiesterase 8B (PDE8B), a cAMP-specific phosphodiesterase highly expressed in the adrenal cortex, in a cohort of patients with adrenal tumours. Clin Endocrinol (Oxf) 2012;77:195-9.

80 Horvath A, Stratakis CA. Unravelling the molecular basis of micronodular adrenal hyperplasia. Curr Opin Endocrinol Diabetes Obes 2008;15:227-33.

81 Horvath $A$, Boikos S, Giatzakis $C$, et al. A genome-wide scan identifies mutations in the gene encoding phosphodiesterase 11A4 (PDE11A) in individuals with adrenocortical hyperplasia. Nat Genet 2006;38:794-800.

82 Gagliardi L, Schreiber AW, Hahn CN, et al. ARMC5 mutations are common in familial bilateral macronodular adrenal hyperplasia. I Clin Endocrinol Metab 2014;99:E1784-92.

83 Alencar GA, Lerario AM, Nishi MY, et al. ARMC5 mutations are a frequent cause of primary macronodular adrenal hyperplasia. J Clin Endocrinol Metab 2014;99: E1501-9.

84 Faucz FR, Zilbermint M, Lodish MB, et al. Macronodular adrenal hyperplasia due to mutations in an armadillo repeat containing 5 (ARMC5) gene: a clinical and genetic investigation. J Clin Endocrinol Metab 2014;99:E1113-19.

85 Assié G, Libé R, Espiard S, et al. ARMC5 mutations in macronodular adrenal hyperplasia with Cushing's syndrome. N Engl J Med 2013;369:2105-14.

86 Lacroix A. Heredity and cortisol regulation in bilateral macronodular adrenal hyperplasia. N Engl J Med 2013:369:2147-9.

87 Assié $G$, Letouzé E, Fassnacht $M$, et al. Integrated genomic characterization of adrenocortical carcinoma. Nat Genet 2014;46:607-12.
88 Bonnet S, Gaujoux S, Launay P, et al. Wnt/B-catenin pathway activation in adrenocortical adenomas is frequently due to somatic CTNNB1-activating mutations, which are associated with larger and nonsecreting tumors: a study in cortisol-secreting and -nonsecreting tumors. J Clin Endocrinol Metab 2011;96:E419-26.

89 Assié $G$, Jouinot A, Bertherat J. The 'omics' of adrenocortical tumours for personalized medicine. Nat Rev Endocrinol 2014;10:215-28.

90 Berthon A, Sahut-barnola I, Lambert-langlais S, et al. Constitutive beta-catenin activation induces adrenal hyperplasia and promotes adrenal cancer development. Hum Mol Genet 2010;19:1561-76.

91 Drelon C, Berthon A, Val P. Adrenocortical cancer and IGF2: is the game over or our experimental models limited? I Clin Endocrinol Metab 2013;98: 505-7.

92 Lacroix A, Bourdeau I, Lampron A, et al. Aberrant G-protein coupled receptor expression in relation to adrenocortical overfunction. Clin Endocrinol (Oxf) 2010;73:1-15.

93 Schteingart DE. The clinical spectrum of adrenocortical hyperplasia. Curr Opin Endocrinol Diabetes Obes 2012;19:176-82.

94 Elbelt U, Trovato A, Kloth M, et al. Molecular and clinical evidence for an ARMC5 tumor syndrome: concurrent inactivating germline and somatic mutations are associated with both primary macronodular adrenal hyperplasia and meningioma. J Clin Endocrinol Metab 2014:jc20142648.

95 Carney JA, Stratakis CA, Young WF. Adrenal cortical adenoma: the fourth component of the Carney triad and an association with subclinical Cushing syndrome. Am J Surg Pathol 2013;37:1140-9.

96 Berthon A, Drelon C, Ragazzon B, et al. WNT/B-catenin signalling is activated in aldosterone-producing adenomas and controls aldosterone production. Hum $\mathrm{Mol}$ Genet 2014;23:889-905.

97 Ragazzon B, Libé R, Assié $G$, et al. Mass-array screening of frequent mutations in cancers reveals RB1 alterations in aggressive adrenocortical carcinomas. Eur J Endocrinol 2014;170:385-91.

98 Stratakis CA. Adrenal cancer in 2013: Time to individualize treatment for adrenocortical cancer? Nat Rev Endocrinol 2014;10:76-8.

99 Ronchi CL, Sbiera S, Leich E, et al. Single nucleotide polymorphism array profiling of adrenocortical tumors - evidence for an adenoma carcinoma sequence?. PLOS ONE 2013;8:e73959.

100 Lila AR, Gopal RA, Acharya SV, et al. Efficacy of cabergoline in uncured (persistent or recurrent) Cushing disease after pituitary surgical treatment with or without radiotherapy. Endocr Pract 2010;16:968-76.

101 Colao A, Petersenn S, Newell-price J, et al. A 12-month phase 3 study of pasireotide in Cushing's disease. N Engl J Med 2012;366:914-24.

102 Fleseriu M, Biller BM, Findling JW, et al. Mifepristone, a glucocorticoid receptor antagonist, produces clinical and metabolic benefits in patients with Cushing's syndrome. J Clin Endocrinol Metab 2012;97:2039-49.

103 Terzolo M, Zaggia B, Allasino B, et al. Practical treatment using mitotane for adrenocortical carcinoma. Curr Opin Endocrinol Diabetes Obes 2014;21:159-65.

104 Tinat J, Bougeard G, Baert-desurmont S, et al. 2009 version of the Chompret criteria for Li Fraumeni syndrome. J Clin Oncol 2009;27:e108-9.

105 Gomez-Sanchez CE. Channels and pumps in aldosterone-producing adenomas. J Clin Endocrinol Metab 2014;99:1152-6. 


\section{Corrections}

Duan K, Gomez Hernandez K, Mete O. Clinicopathological correlates of adrenal Cushing's syndrome. J Clin Pathol 2015;68:175-186. doi:10.1136/jclinpath-2014-202612

The provenance and peer review statement should read: Commissioned; internally peer reviewed.

J Clin Pathol 2015;68:e2. doi:10.1136/jclinpath-2014-202612corr1

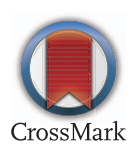

